\title{
Responses of copepods to dissolved free amino acids
}

\author{
C. W. Gill, S. A. Poulet \\ Station d'Océanologie et de Biologie Marine, CNRS, Place Teissier, F-29211 Roscoff, France
}

\begin{abstract}
The first maxilla (M1) beating frequency of Temora longicornis, which is considered to be an index of feeding behaviour, was measured using a computerized micro-impedance technique, in filtered seawater as a control, and after exposure to 9 different particle-free mixtures of equimolar $\left(10^{-6}\right.$ $M$ amino acids dissolved in seawater. Mixtures containing 20 dissolved free amino acids (ASP, GLU, ASN, SER, THR, GLN, HIS, GLY, ARG, $\beta$-ALA, TAUR, TYR, AABA, VAL, TRP, PHE, ILE, LEU, ORN and LYS) were all detected by this copepod. Mixture 8 , containing SER, THR, GLY and TYR, caused an increase inactivity for only $30 \%$ of copepods tested, so not all amino acids are stimulatory in copepods. Chemical stimulation and responses were reflected in an increase in appendage beat frequency. On ayerage, strongest responses were recorded for Mixture 1, containing ASP, GLU, ASN, SER, GLN and HIS, Mixture 2, containing GLY, TYR, PHE, LEU, ORN and LYS, and Mixture 7, containing ASP and GLU. Responses corresponded to increases in frequency up to $5.6 \mathrm{~Hz}$, and varied according to the number and combination of amino acids present in the mixture. Amino acids are among the bioactive molecules responsible for triggering chemosensory feeding responses in copepods.
\end{abstract}

\section{INTRODUCTION}

Copepods are not indiscriminate feeders and the behavioural selection of particles is under sensory control. Mechanoreception is important for the remote detection, oriented capture and handling of large particles (Paffenhöfer et al. 1982, Cowles \& Strickler 1983, Price \& Paffenhöfer 1984) and it is known that the size (Price et al. 1983), shape (Gifford et al. 1981) and concentration of particles (Price \& Paffenhöfer 1985, 1986) affect selection. Chemoreception is being increasingly implicated in feeding, as copepods may also be able to select or reject captured food according to its nutritional value (Poulet \& Marsot 1978, 1980, Donaghay \& Small 1979, Huntley et al. 1983, Paffenhöfer \& Van Sant 1985). Copepods respond to chemosensory stimulation alone in the form of filtered phytoplankton exudates (Buskey 1984, Gill \& Harris 1987); however, the chemicals responsible for stimulating feeding in copepods are, as yet, unidentified.

Many organic compounds are found within phytoplankton (e.g. Fogg 1966), and it has been suggested that dissolved organic compounds exuded by phytoplankton are retained in a boundary layer surrounding the cell, which may be detected by copepods (e.g. Andrews 1983). There are various substances, including peptides, fatty acids, carbohydrates and vitamins, which have the potential to act as chemical agents triggering feeding, and amino acids can be considered among these for the following reasons: (1) amino acids are of low molecular weight and soluble in water; (2) with reference to phytoplankton, amino acids occur intracellularly and are excreted extracellularly (Poulet \& Martin-Jezequel 1983, Admiraal et al. 1984, 1986); amino acids are lost from senescent cells (Poulet \& Martin-Jezequel 1983, Hammer \& Katner 1986); and amino acids may be released by cell breakage during zooplankton grazing ('sloppy feeding'; Lampert 1978, Olsen et al. 1986, Williams \& Poulet 1986); (3) electrophysiological and behavioural studies have shown that amino acids stimulate feeding in higher crustaceans (Fuzessery \& Childress 1975, Hamner \& Hamner 1977. Atema 1985).

Amino acids occur naturally in seawater, although their distribution is patchy and the total concentration is variable (e.g. Braven et al. 1984). In the past, the occurrence of amino acids was not thought to be at a high enough concentration to be chemically detectable to copepods. High performance liquid chromatography (HPLC) has allowed the accurate measurement of dissolved free amino acids (DFAA) and the background level of DFAA in seawater is now known to be generally less than $10^{-8} M$ (e.g. Mopper \& Linroth 1982, Carlucci et al. 1986). Higher concentrations are meas- 
ured within microlayers associated with zooplankton grazing on phytoplankton, where DFAA can be $10^{-7}$ to $10^{-6} \mathrm{M}$ (Williams \& Poulet 1986, Poulet unpubl.); within phytoplankton cells where they are $10^{-6}$ to $10^{-4} \mathrm{M}$, and extracellularly where they range between $10^{-8}$ and $10^{-4} M$ (Poulet \& Martin-Jezequel 1983, Poulet unpubl.). It is likely that the concentration of the chemical signal which triggers a behavioural response will be within the range of concentrations occurring in nature.

Copepods swim by beating the cephalic appendages, and unless disturbed, Temora longicornis swims continuously (Gill 1987). Chemosensory receptors have been identified on the cephalic appendages of copepods (Friedman \& Strickler 1975, Friedman 1980, Gill 1986). The first maxilla (M1) is involved in both swimming and feeding movements, and the beat frequency of the $\mathrm{M} 1$ increases in the presence of food stimuli such as diatom cells or filtrates of homogenized phytoplankton cells (Gill \& Harris 1987). Thus, a measurement of $\mathrm{M} 1$ activity reflects feeding behaviour.

The objective of this study was to measure the M1 beat frequency of Temora longicornis in the presence of mixtures of amino acids, and so determine whether these chemical compounds are detected by copepods, and if they can stimulate feeding behaviour.

\section{MATERIALS AND METHODS}

Copepods were collected from the English Channel off Roscoff (France) and kept at $15 \mathrm{C}^{\circ}$ Adult female Temora longicornis were sorted from the samples and kept in filtered seawater ( 1 um pore diameter Whatman glass fibre filter GFC) overnight. Experimental conditions were characterized by the computerized microimpedance system previously described by Gill \& Poulet (1986). Recordings were made in a flow-through chamber of $125 \mathrm{ml}$ volume which was gravity-fed at a rate of $10 \mathrm{ml} \mathrm{min}{ }^{-1}$ with filtered seawater or with mixtures of dissolved amino acids. The experimental system was maintained at $15 \mathrm{C}^{\circ}$ in a constant temperature room.

Individual copepods were restrained by a suction tube technique (Gill 1987). Microelectrodes (Gill \& Poulet 1986) were used to make direct recordings of the M1 beating patterns in filtered seawater (control) and after 10 min exposure to various particle-free mixtures of L-amino acids (Sigma Co.) dissolved in filtered seawater at a concentration of $10^{-6} M$ (experiment). A background level concentration $<10^{-6} \mathrm{M}$ for DFAA was detected off Brittany, France (Braven et al. 1984, Poulet et al 1984, 1985) with HPLC which was also used
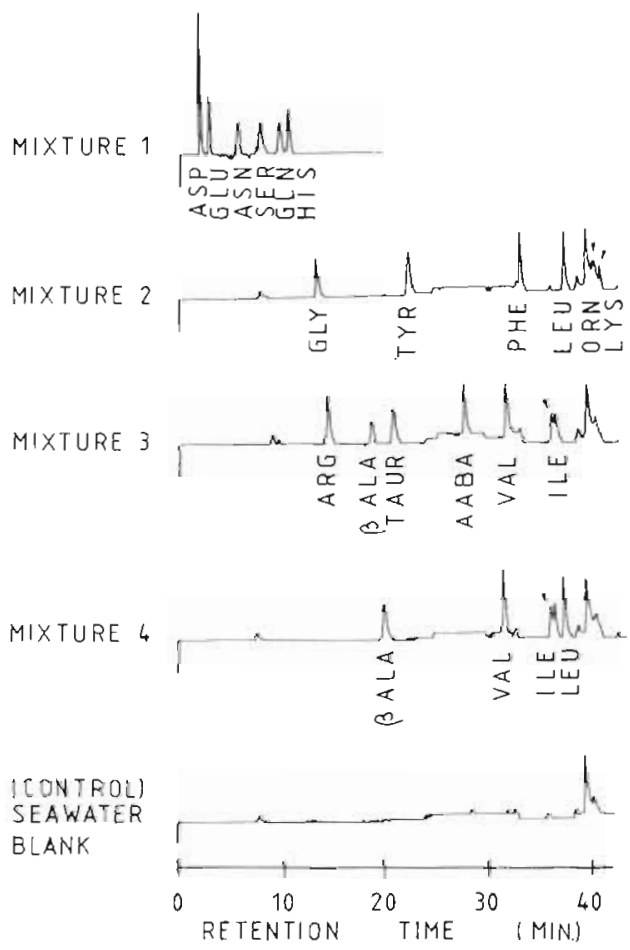
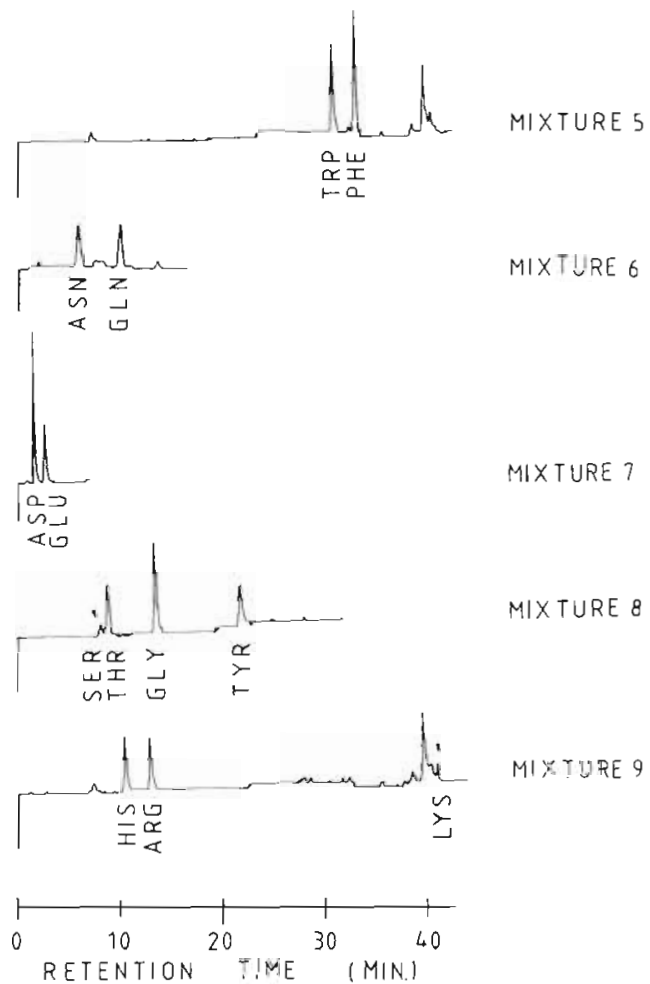

MIXTURE 7

MIXTURE 8

MIXTURE 9

Fig. 1. HPLC chromatograms of DFAA in control $\left(<10^{-8} \mathrm{M}\right)$ and test mixtures $\left(10^{-6} \mathrm{M}\right)$, showing constituent amino acids. Key: AABA, $\alpha$-amino butyric acid; $\beta$-ALA, $\beta$-alanine; ARG, arginine; ASN, asparagine; ASP, aspartic acid; GLN, glutamine; GLU, glutamic acid; GLY, glycine; HIS, histidine; ILE, isoleucine; LEU, leucine; LYS, lysine; ORN, ornithine; PHE, phenylalanime; SER, serine; TAUR, taurine; THR, threonine; TRP, tryptophan; TYR, tyrosine; VAL, valine 
to monitor the DFAA levels of control and experimental solutions (Lindroth \& Mopper 1979).

The responses of 10 copepods were measured for each of 9 DFAA mixtures containing altogether 20 amino acids (Fig. 1). Recordings were of 3 min duration and stored on disc. Student's t-test was used to compare the $\mathrm{M} 1$ beat frequency of each individual under control and experimental conditions. Spectral and autocorrelation analyses (Bendat \& Piersol 1971) were made for selected sections of traces (time series corresponding to 500 to 2000 data points) using the SSP-IBM 1130 package to compare the behavioural responses in terms of beating frequency in the 1 to $100 \mathrm{~Hz}$ range (see also companion article, Poulet \& Gill 1988).

\section{RESULTS}

The DFAA content of the filtered seawater controls was very low $\left(<10^{-8} M_{i}\right.$ Fig. 1). Fig. 1 shows chromatograms for all the DFAA Mixtures 1 to 9 at the same scale. Peaks correspond to the individual amino acids added to filtered seawater at a concentration of $10^{-6} \mathrm{M}$. Because of the difference between the levels of amino acids in the seawater controls and the DFAA mixtures, it can be assumed that the copepods responded to only those DFAA that were added to filtered seawater.

Mixtures 1 to 3 , each containing 6 different amino acids, were chosen from those that occur naturally and are the most abundant in seawater. Exposure to DFAA Mixtures 1 to 3 caused significant increases $(p<0.01$, Student's t-test) of $\leqslant 5.1 \mathrm{~Hz}$ in the $\mathrm{M} 1$ beat frequency of all individuals tested (Fig. 2A, C). Thus it is clear that Temora longicornis detects and responds to mixtures of amino acids.

To determine if the copepods' response was related to the chemical structure of the amino acids, additional DFAA mixtures containing 2 to 4 amino acids but differing in their side chains or R-group structure were tested. Mixtures 4 to 9 (Fig. 1) contained some amino acids previously used in Mixtures 1 to 3, and also THR
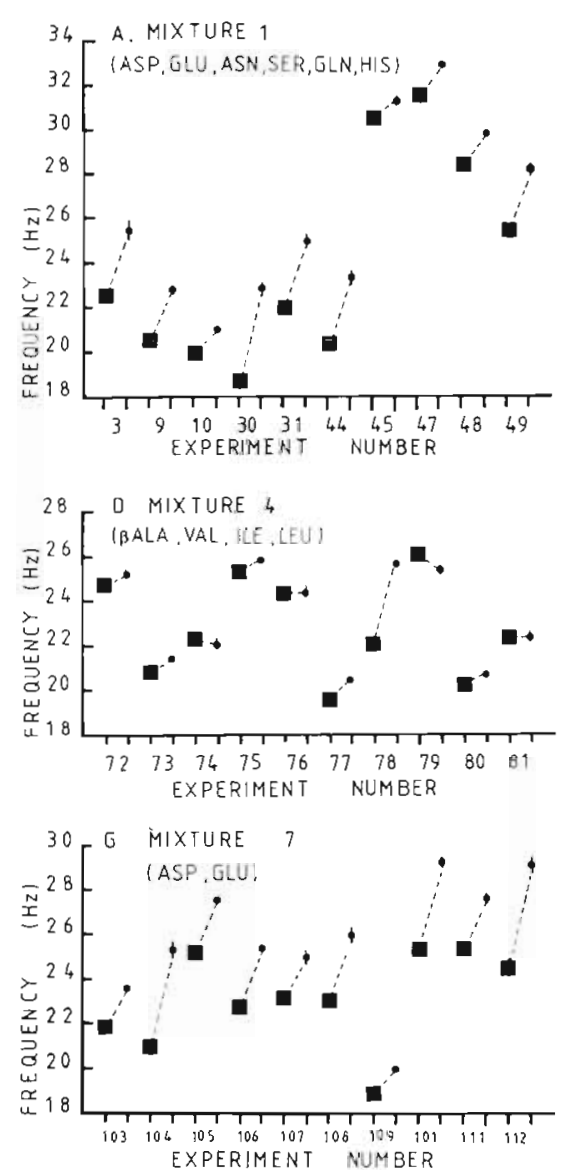
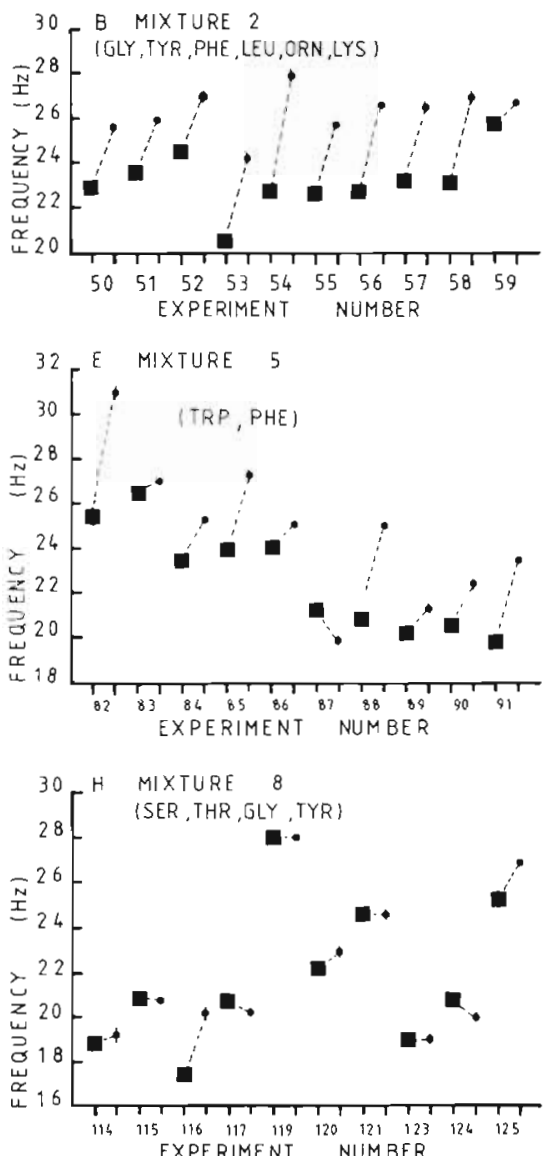
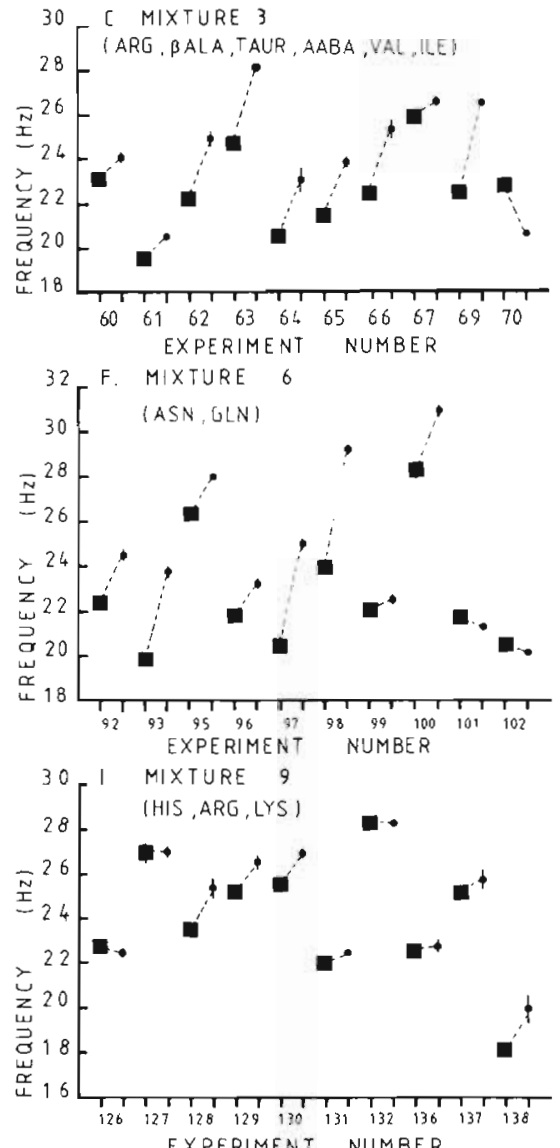

EXPERIMENT NUMBER

Fig. 2. Temora longicornis. Response to DFAA Mixtures 1 to 9 (see Fig. 1 for key to DFAAs in mixtures). (-) Mean frequency for pre-starved copepods in filtered seawater (control); ( $\bullet$ mean frequency after 10 min exposure to Mixtures 1 to 9 . Vertical bars show standard deviation. Changes in frequency are significant at $p<0.05$ (Student's $t$-test) except for the following experiments: Mixture 4 Nos. 74, 76, 81; Mixture 6 No. 99; Mixture 8 Nos. 114, 115, 119, 121, 123; Mixture 9 Nos. 126, 127, 132, 136 
and TRP (see Fig. 1 for key to amino acid abbreviations). The copepods' responses varied according to the mixture tested (Fig. 2D to I). Frequency changes were $<5.6 \mathrm{~Hz}$. Mixtures 5 (Fig. 2E, aromatic ring R-group) and 6 (Fig. 2F, amide R-group) produced levels of response similar to Mixtures 1 to 3 . Mixture 7 was the most stimulatory (Fig. 2G, carboxyl R-group) containing only ASP and GLU, and producing higher increases in frequency compared to Mixture 1 (Fig. 2A) containing ASP and GLU with 4 other amino acids. Increases in frequency were generally lower and more variable for Mixture 4 (Fig. 2D, hydrocarbon R-group), Mixture 8 (Fig. 2H, hydroxyl R-group), and Mixture 9 (Fig. 2I, aliphatic R-group) compared to the mixtures containing 6 amino acids (Fig. $2 \mathrm{~A}$ to $\mathrm{C}$ ). Changes in frequency were significant $(\mathrm{p}<0.05)$ for $70 \%$ of individuals with Mixture 4 , and for $60 \%$ of individuals with Mixture 9. Mixture 8, containing SER, THR, GLY and TYR was the least stimulatory, and $70 \%$ of copepods showed no significant increase in activity. However, SER was included in Mixture 1 and GLY was included in Mixture 2, mixtures which were stimulatory. Therefore, it would appear that Temora longicornis detects and responds to some DFAA mixtures, but not to others.

Samples of impedance traces of $\mathrm{M} 1$ activity given in Fig. 3 demonstrate how the beat frequency increased

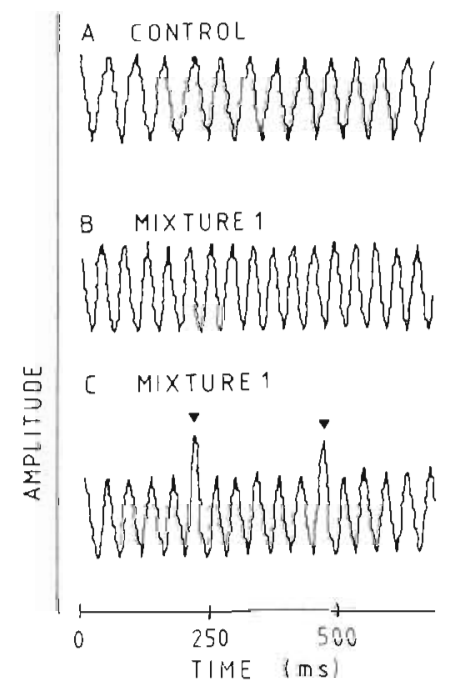

Fig. 3. Example of impedance traces of $M 1$ beating patterns (Expl 30). (A) Filtered seawater (control), frequency $18.2 \mathrm{~Hz}$. (B) Mixture 1, 23.8 Hz. (C) Mixture 1, antennule (A1) flicking ( $)$, possibly enhancing chemoreception

after exposure to Mixture 1 (Fig. 2A, B). Temora longicornis also frequently flicked its antennules (A1) backwards, and this additional movement produced a peak of higher amplitude which is shown imposed on the $\mathrm{M} 1$ beating pattern in Fig. 2C.
The spectral and autocorrelation analyses were carried out to further discriminate and compare the frequencies of the M1 beat patterns of Temora longicornis under control and test conditions. Only one major frequency peak was found (Fig. 4A). This shift in frequency between control and experiment peaks (Fig. $4 \mathrm{~A}$, arrow) confirms that chemical stimulation by amino acids modifies the frequency of the appendage movements. The example shown in Fig. 4 applies to Mixture 1 , and similar results were obtained for the other mixtures of amino acids which had a stimulatory effect on copepods. The shift in the frequency peaks computed for control and test conditions was significant (e.g. autocorrelation, $p=0.05$ ), as shown in Fig. 2B. This gives an index of the copepods response to DFAA.

\section{DISCUSSION}

It has been known for some 35 yr that copepods modify their activity in the presence of phytoplankton exudates (Bainbridge 1953). Active chemosensory feeding responses were first demonstrated by Poulet \& Marsot (1978) who showed that copepods select microcapsules enriched with phytoplankton homogenate in preference to non-enriched microcapsules. The experiments reported here show that the first bioactive molecules to be identifed as stimulating feeding in copepods are amino acids. However, other chemical compounds are also suspected to be stimulatory. Laboratory studies by Poulet \& Ouellet (1982) showed that DFAAs can play a role in the swarming behaviour of copepods, so it is likely that feeding and swimming are influenced by the chemosensory detection of DFAAs. Chemical signals in the marine environment are complex, and as DFAAs are stimulatory, they serve to identify food that attracts copepods. Certain bloomforming dinoflagellates and their homogenized filtrates suppress grazing in copepods (Fiedler 1982, Huntley et al. 1983, 1986, Ives 1986, Gill \& Harris 1987), so there are other naturally occurring chemical compounds, as yet unidentified, that are repellent and even toxic to copepods. Therefore, it appears that copepods use chemical clues to recognize and differentiate between potential food items

If copepods detect molecules from within a specific concentration range, then the threshold detection level is of major importance. There is a link between the sensory response of copepods, the level of DFAA occurring naturally in seawater, and the concentration of DFAA related to the intracellular and extracellular pools of phytoplankton. Fuzessery \& Childress (1975) and Poulet \& Ouellet (1982) showed that zooplanktonic crustaceans give behavioural responses at DFAA concentrations ranging from $10^{-2}$ to $10^{-8} \mathrm{M}$. We carried out 


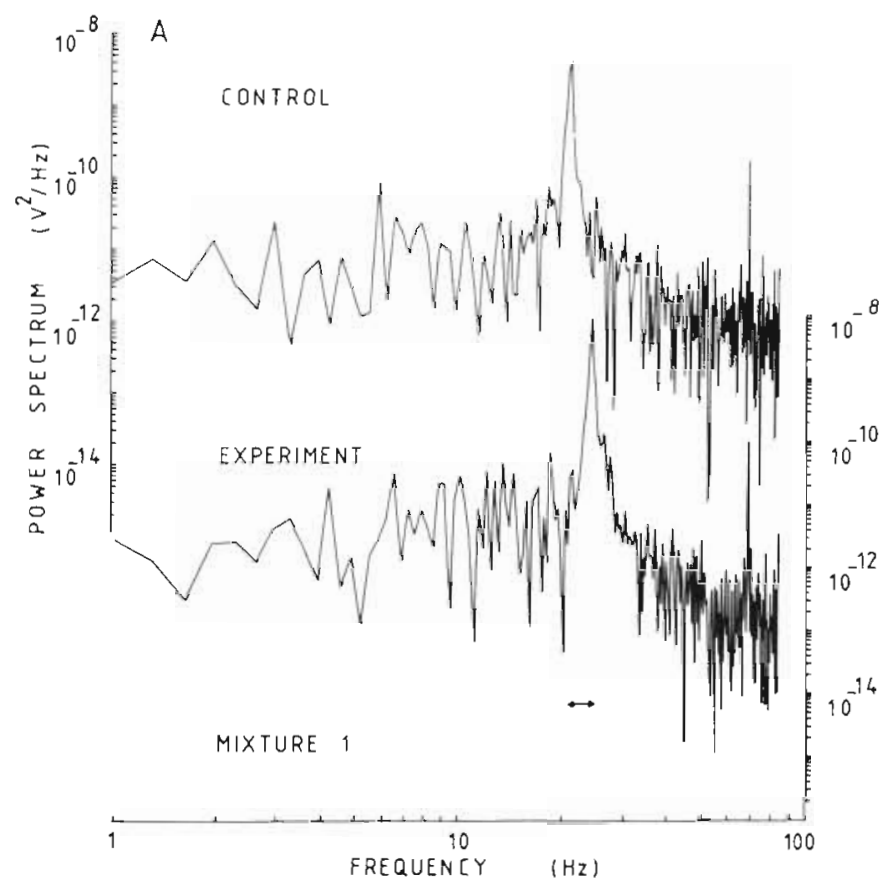

B

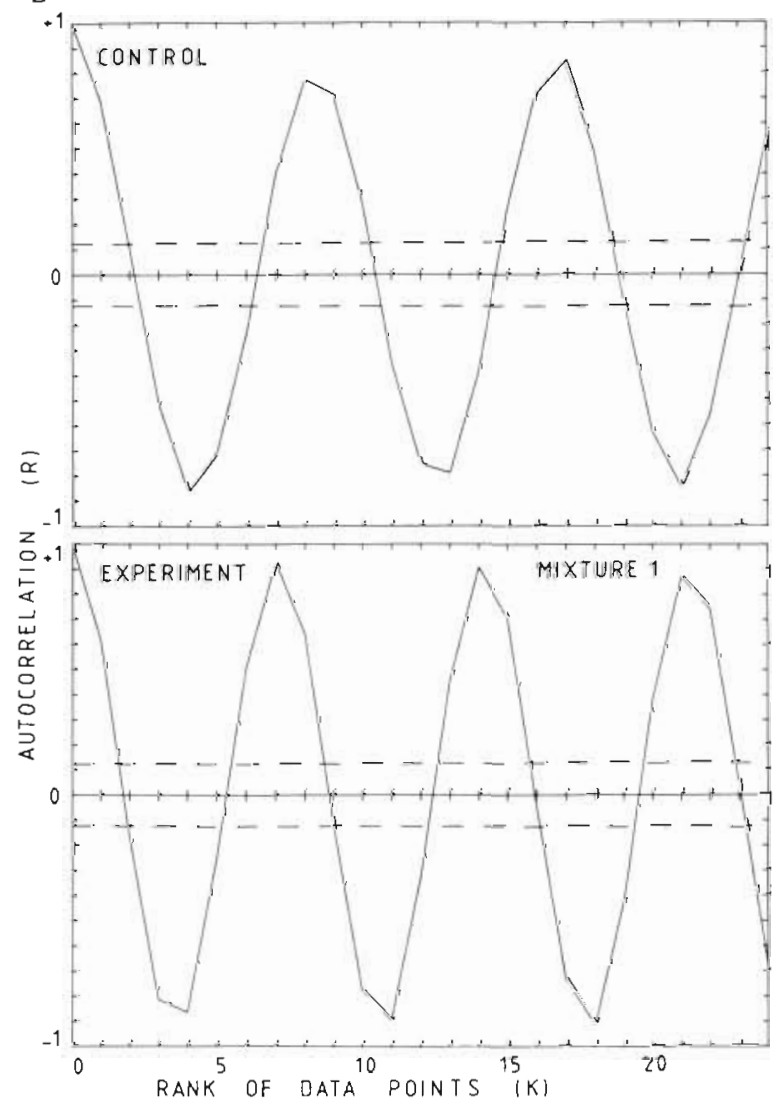

Fig. 4. Example of spectral and autocorrelation analyses for control and test DFAA Mixture 1. (A) Spectral analysis; (B) autocorrelation analysis. Dashed lines: confidence limits $(p=$ 0.05 ). Time series correspond to 512 data points selected from traces recorded in Expt 44. V: amplitude of movements (mV); $\mathrm{Hz}$ : frequency in cycles per second preliminary experiments to determine the concentration at which Temora longicornis responds to DFAA using mixtures of $10^{-8}, 10^{-6}, 10^{-4}$ and $10^{-3} \mathrm{M}$, and results indicated that $10^{-8} \mathrm{M}$ was often undetected, and $10^{-3} M$ was either undetected or inhibitory. Coastal zone seawater generally contains DFAA at a concentration of $<10^{-7} M$ (Braven et al. 1984, Poulet et al. 1985). Release of DFAA from phytoplankton produces a rise from $10^{-8}$ to $10^{-6} M$ (e.g. Hammer et al. 1981, Poulet \& Martin-Jezequel 1983). An increase of 10 to 100 times the background level corresponds to the range of increase in signal strength at which chemosensory transduction can take place (Atema 1985). Therefore, the concentration of $10^{-6} \mathrm{M}$ at which $T$. longicornis responded to DFAA mixtures in our experiments is realistic.

The combination of amino acids within Mixtures 1 to 9 (Fig. 2) influenced the detection and degree of response shown by Temora longicornis. This supports the concept of a species-specific 'chemical print' in phytoplankton (Admiraal et al. 1986, Martin-Jezequel et al. 1988), which influences sensory detection and recognition of food by copepods. This is in agreement with other workers who found planktonic crustaceans to be specifically affected by amino acids (Fuzessery \& Childress 1975, Hamner \& Hamner 1977, Poulet \& Ouellet 1982). Considering the chemical structure of the amino acids, and the combinations tested, the results for Mixtures 4 to 9 require further work before making any definite conclusions on the relationship between the chemical structure of DFAA (e.g. end radicals) and the behavioural responses of copepods. However, molecular size and chemical structure may perhaps affect detection as Mixture 7, containing ASP and GLU characterized by the carboxyl R-group (Fig. 2G), was the most stimulatory of Mixtures 4 to 9 .

The number of amino acids in a mixture may be important, as Mixtures 1 to 3 containing 6 amino acids (Fig. $2 \mathrm{~A}$ to $\mathrm{C}$ ), were more stimulatory than those containing 2 to 4 amino acids (Fig. 2D to I). Individual amino acids have not been found to modify planktonic crustacean behaviour (e.g. Hamner \& Hamner 1977) but it is unlikely that amino acids would normally be encountered in isolation, so mixtures containing several DFAA are more comparable to chemical signals which occur naturally.

The principial effect the DFAA mixtures had on the behaviour of Temora longicornis was to increase M1 beat frequency. This corresponds to an increase in the rate of water flow past the copepods' chemoreceptors, enhancing their ability to detect changes in the chemical environment. Distance chemoreception probably involves chemoreceptors on the copepods' antennules (A1). By increasing the water flow past the copepods' chemoreceptors, A.1 flicking (Fig. 3C; Griffiths \& Frost 
1976, Hamner \& Hamner 1977, Gill 1987), may also enhance chemoreception, in analogy with A.1 flicking in lobsters (Schmitt \& Ache 1979) and sniffing in humans. The increase in speed of the feeding current may deform the 'active space' of dissolved molecules which surrounds a phytoplankton cell (Andrews 1983). This will produce a chemical gradient, thereby giving the copepod advance warning of the cell's position, and decreasing the cell's detection distance. Production of a chemical gradient in the order of 10 to $100 \times 10^{-8} \mathrm{M}$ is probably sufficient for planktonic crustaceans to track food by following scent trails (Hamner \& Hamner 1977) and by locating the position of nearby cells before their capture. The increase in speed of the feeding current also increases the number of particles encountered (Gerritsen 1980, Poulet et al. 1986), and thereby increases feeding rate. As our experiments were carried out in the absence of particles, the increase in $M 1$ beating speed obtained for $T$ longicornis may also represent searching behaviour, which will increase the copepod's chance of encountering the source of chemical stimulation. This strategy may help copepods to survive in a nutritionally dilute environment (Conover 1968).

Chemosensory stimulation alone in the form of particle-free mixtures of DFAA (Fig. 2A to $\mathrm{H}$ ), produced an increase in the M1 beat frequency of Temora longicornis which was less than that obtained under similar experimental conditions with intact phytoplankton cells (Gill \& Harris 1987). Both chemosensory and mechanosensory stimulations may be necessary to produce the optimum feeding response in $T$. longicornis. DFAAs are chemical components of phytoplankton (e.g. Fogg 1966). T. longicomis gave the same increase in $\mathrm{M} 1$ beat frequency to DFAA Mixtures 1 to 3 (Fig. 2A to $C$ ), and to particle-free homogenized diatom cells (Gill \& Harris 1987). This provides further evidence that DFAAs are used to recognize food, and are the bioactive molecules responsible for triggering chemosensory feeding responses in copepods.

How and where do amino acids occur naturally at about $10^{-6} \mathrm{M}$, which was the level we found triggered a chemosensory reponse in Temora longicornis? We know that phytoplankton species differ in their relative intracellular abundance of free amino acids, but their concentration is detectable by copepods (Admiraal et al. 1986, Martin-Jezequel et al. 1988). Growing phytoplankton cells release minimal amounts of amino acids, but amino acids are released by senescent cells during post-bloom conditions (Hammer et al. 1981, Poulet \& Martin-Jezequel 1983, Hammer \& Eberlein 1986, Hammer \& Kattner 1986, Poulet unpubl.J. DFAAs can originate from faecal pellets a wide spectrum of amino acids. These can be released when copepods disrupt the pellet membrane during feeding/coprophagy
(Paffenhöfer \& Strickland 1970, Poulet et al. 1986). 'Sloppy feeding' by zooplankton is known to release 17 to $21 \%$ of dissolved carbon contained in phytoplankton cells, and probably also amino acids (Lampert 1978, Olson et al. 1986, Williams \& Poulet 1986). The fluxes of DFAA related to the processes listed above contribute to amino acids being concentrated in narrow depth horizons (1 to $10 \mathrm{~m}$ ), associated with maxima of zooplankton abundance (Mopper \& Lindroth 1982, Poulet et al. 1985, Williams \& Poulet 1986, Poulet unpubl.). Concentrated pools of amino acids signal the presence of food, so may attract nearby copepods, and help to maintain aggregations of grazers in the vicinity of the food stock.

Acknowledgements. C. W Gill gratefully acknowledges receipt of a Royal Society of London post-doctoral fellowship in the European Science Exchange Programme. This work is a contribution of CNRS (Incitation Europe and DRCI, contracts nos. 8650N5072 and 8692N920198) and of GREPMA (Groupe Regional d'Etudes Pelagiques Manche-Atlantique). Thanks are due to referees for their positive comments

\section{LITERATURE CITED}

Admiraal, W., Laane, R. W. P. M., Peletier, H. (1984). Participation of diatoms in the amino acids cycle of coastal waters; uptake and excretion in cultures. Mar Ecol. Prog. Ser. 15: 303-306

Admiraal, W., Peletier, H., Laane, R. W. P. M. (1986). Nitrogen metabolism of marine planktonic diatoms; excretion, assimilation and cellular pools of free amino acids in seven species with different cell size. J. exp. mar. Biol. Ecol. 98: $241-263$

Andrews, J. C. (1983). Deformation of the active space in the low Reynolds number feeding current of calanoid copepods. Can. J. Fish. Aquat. Sci. 40: 1293-1302

Atema, J. (1985). Chemoreceptrion in the sea: adaptations of chemoreceptors and behaviour to aquatic stimulus conditions. In: Laverack, M. S. (ed.) Physiological adaptations of marine animals. Symp. Soc. Exp. Biol. Company of Biologists Ltd, Cambridge, p. 387-423

Bainbridge, R. (1953). Studies on the interrelationships of zooplankton and phytoplankton. J. mar. biol. Ass. U. K. 32 : $385-447$

Bendat, J. S., Piersol, A. G. (1971). Random data. Analysis and measurement procedures. Wiley, London

Braven, J., Evens, R., Butler, E. I. (1984). Amıno acids in sea water. Chem. Ecol. 2: 11-21

Buskey, E. J. (1984). Swimming pattern as an indicator of the roles of copepods sensory systems in the recognition of food. Mar. Biol. 79: 165-175

Carluccl, A. F., Craven, D. B., Robertson, K. J., Henrichs, S. M. (1986). Microheterotrophic utilization of dissolved free amino acids in depth profiles of Southern California Borderland basin waters. Oceanologica Acta 9: 89-96

Conover, R J. (1968). Zooplankton life in a nutritionally dilute environment. Am. Zool. 8: 107-118

Cowles, T J., Strickler, J. R. (1983). Characterization of feeding activity patterns in the planktonic copepod Centropages typicus Kroyer under various food conditions. Limnol. Oceanogr. 28: 106-115 
Donaghay, P. L., Small, L. F. (1979). Food selection capabilities of the estuarine copepod Acartia clausi. Mar Biol. 52: $137-146$

Fiedler, P. C. (1982). Zooplankton avoidance and reduced grazing responses to Gymnodinium splendens (Dinophyceae). Limnol. Oceanogr. 27: 961-965

Fogg, G. E. (1966). The extracellular products of algae. Oceanogr. mar. Biol. A. Rev, 4: 195-212

Friedman, M. M. (1980). Comparative morphology and functional significance of copepod receptors and oral structures. In: Kerfoot W C. (ed.) Evolution and ecology of zooplankton communities. University Press of New England, Hanover, p. 185-197

Friedman, M. M., Strickler, J. R. (1975). Chemoreceptors and feeding in calanoid copepods (Arthropoda: Crustacea). Proc. natl Acad. Sci. USA 72: 4185-4188

Fuzessery, Z. M., Childress, J. J. (1975). Comparative chemosensitivity to amino acids and their role in the feeding activity of bathypelagic and littoral crustaceans. Biol. Bull. mar, biol. Lab., Woods Hole 149: 522-538

Gerritsen, J. (1980). Adaptative response to encounter problems. In: Kerfoot, W. C. (ed.) Evolution and ecology of zooplankton communities. University Press of New England. Hanover, p. 52-62

Gifford, D. J., Bohrer, R. N., Boyd, C. M. (1981). Spines on diatoms: do copepods care? Limnol. Oceanogr. 26: $1057-1061$

Gill, C. W. (1986). Suspected mechano- and chemosensory structures of Temora longicornis (Copepoda: Calanoida). Mar. Biol. 93: 449-457

Gill, C. W (1987). Recording the beat patterns of the second antennae of calanoid copepods, with a micro-impedance technique. Hydrobiologica 148: 73-78

Gill, C. W. Harris, R. P. (1987). Behavioural responses of the copepods Calanus helgolandicus and Temora longicornis to dinoflagellates. J. mar biol. Ass. U. K. 67. 785-801

Gill, C. W., Poulet, S. A. (1986). Utilization of a computerized micro-impedance system for studying the activity of copepod appendages. J. exp. mar. Biol. Ecol. 101. 193-198

Griffiths, A. M., Frost, B. W (1976). Chemical communication in the marine planktonic copepods Calanus pacificus and Pseudocalanus sp. Crustaceana 30: 1-8

Hammer, K. D., Brockmann, U. H., Kattner, G. (1981). Release of dissolved free amino acids during a bloom of Thalassiosira rotula. Kieler Meeresforsch. (Sonderh.) 5: 101-109

Hammer, K. D., Eberlein, K. (1986). Parallel experiments with Thalassiosira rotula in outdoor plastic tanks: development of dissolved free amino acids during an algal bloom. Mar. Chem. 10: 533-544

Hammer, K. D., Kattner, G. (1986). Dissolved free amino acids in the marine environment: a carbon to nitrogen ratio shift during diatom blooms. Mar Ecol. Prog. Ser. 31: 35-45

Hamner, P., Hamner, W. M. (1977). Chemosensory tracking of scent trails by the planktonic shrimp Acetes sibogae australis. Science 195: 881-888

Huntley, M. E., Barthel, K.-G., Star, J. L. (1983). Particle rejection by Calanus pacificus: discrimination between similar-sized particles. Mar. Biol. 74: 151-160

Huntley, M. E., Sykes, P., Rohan, S., Marin, V. (1986). Chemically-mediated rejection of dinoflagellate prey by the copepods Calanus pacificus and Paracalanus parvus: mechanism, occurrence and significance. Mar. Ecol. Prog. Ser. 28: $105-120$

Ives, J. D. (1986). The relationship between Gonyaulax tamarensis cell toxin levels and copepod ingestion rates. In: Anderson, D. M., White, A. W., Baden, D. G. (eds.) Toxic dinoflagellates. Elsevier, New York, p. 413-418
Lampert, W (1978). Release of dissolved organic carbon by grazing zooplankton. Limnol. Oceanogr. 23: 831-834

Lindroth, P., Mopper, K. (1979). High performance liquid chromatographic determination of subpicomole amounts of amino acids precolumn fluorescence derivatization with o-phthaldialdehyde. Analyt. Chem. 51: 1667-1674

Martin-Jezequel, V., Poulet, S. A., Harris, R. P., Moal, J., Samain, J. F. (1988). Interspecific and intraspecific composition and variation of free amino acids in marine phytoplankton. Mar Ecol. Prog. Ser. (in press)

Mopper, K., Lindroth, P. (1982). Diel and depth variations in dissolved free amino acids and ammonium in the Baltic Sea determined by shipboard HPLC analysis. Limnol. Oceanogr 27: 336-347

Olsen, Y., Varum, K. M., Jensen, A. (1986). Some characteristics of the carbon compounds released by Daphnia. J. Plankton Res. 8: 505-517

Paffenhöfer, G. A., Strickland, J. D. H. (1970). A note on the feeding of Calanus helgolandicus on detritus. Mar. Biol 5: 97-99

Paffenhöfer, G. A., Strickler, R. J., Alcaraz, M. (1982). Suspension feeding by herbivorous calanoid copepods: a cinematographic study. Mar. Biol. 67: 193-199

Paffenhöfer, G. A., Van Sant, K. B. (1985). The feeding response of a marine planktonic copepod to quantity and quality of food. Mar. Ecol. Prog. Ser. 27 55-65

Poulet, S. A., Marsot, P. (1978). Chemosensory grazing by marine calanoid copepods (Arthropoda: Crustacea). Science 200: 1403-1405

Poulet, S. A., Marsot, P. (1980). Chemosensory feeding and food gathering by omnivorous marine copepods. In: Kerfoot, W. C. (ed.) Evolution and ecology of zooplankton communities. University Press of New England, Hanover, p. $198-218$

Poulet, S. A., Gill, C. W (1988). Spectral analyses of movements made by the cephalic appendages of copepods. Mar Ecol. Prog. Ser. 43: 259-267

Pouiet, S. A., Harris, R. P., Martın-Jezequel, V., Moal, J., Samain, J. F. (1986). Free amino acids in copepods faecal pellets. Oceanologica Acta 9: 191-197

Poulet, S. A., Martin-Jezequel, V (1983). Relationships between dissolved free amino acids, chemical composition and growth of the marine diatom Chaetoceros debile. Mar Biol. 77: 93-100

Poulet, S. A., Martin-Jezequel, V., Delmas, D. (1985). Gradient of dissolved free amino acids and phytoplankton in a shallow bay. Hydrobiologia 121: 11-17

Poulet, S. A., Martin-Jezequel, V., Head, R. N. (1984). Distribution of dissolved free amino acids in the Ushant front region. Mar Ecol. Prog. Ser. 18: 49-55

Poulet, S. A., Ouellet, G. (1982). The role of amino acids in the chemosensory swarming and feeding of marine copepods. J. Plankton Res. 4: 341-361

Price, H. J., Paffenhöfer, G. A. (1984). Effects of feeding experience in the copepod Eucalamus pileatus: a cinematographic study. Mar. Biol. 84: 35-40

Price, H. J., Paffenhofer, G. A. (1985). Perception of food availability by calanoid copepods. Arch. Hydrobiol. Beih. Ergeb. Limnol. 21: 115-124

Price, H. J., Paffenhöfer, G. A. (1986). Effects of concentration on the feeding of the marine copepod in algal monocultures and mixtures. J. Plankton Res. 8: 119-128

Price, H. J., Paffenhöfer, G. A., Strickler, J. R. (1983). Modes of cell capture in calanoid copepods. Limnol. Oceanogr 28: 116-123

Schmitt, B. C., Ache, B. W. (1979). Olfaction: responses of a decapod are enhanced by flicking. Science 205: 204-206 
Williams, R, Poulet, S. A. (1986). Relationship between the zooplankton, phytoplankton, particulate matter and dis- solved free amino acids in the Celtic Sea. Mar. Biol. 90: 279-284

This article was submitted to the editor; it was accepted for printing on January 29, 1988 